\title{
PULL-OUT BEHAVIOR OF CFRP GROUND ANCHORS WITH TWO-STRAP ENDS
}

\author{
Haifeng Fan, Anastasios P. Vassilopoulos, Thomas Keller \\ Composite Construction Laboratory (CCLab), École Polytechnique Fédérale de Lausanne (EPFL), \\ Station 16, Bâtiment BP, CH-1015 Lausanne, Switzerland
}

\begin{abstract}
Pull-out experiments were performed on three carbon fiber-reinforced polymer (CFRP) ground anchors simulating their applications in different rock types which provided different confinement levels. The CFRP tendons comprised, on the ground side, a prefabricated conical anchor body of high-strength grout in which two CFRP straps were embedded. The anchors reached an average load-bearing capacity of $1384 \mathrm{kN}$ with final failure occurring in the CFRP straps. Grout failure was successfully prevented by an adequate grout selection and installation of CFRP confinement rings to balance spreading forces at the strap ends. The confinement level provided by the surrounding media influenced the activation of the CFRP components in the anchor body by influencing the friction at the CFRP/grout interfaces.
\end{abstract}

\section{KEYWORDS}

Carbon fiber-reinforced polymer; Ground anchor, Two-strap end; Confinement; Pull-out behavior.

\section{INTRODUCTION}

Fiber reinforced polymer (FRP) tendons are increasingly used to replace conventional steel tendons in ground anchors, taking advantage of their high strength-to-weight ratio and good corrosion resistance. The applications of AFRP and CFRP tendons, especially in permanent prestressed cases, have been reported since 1990 (Tokyo Rope Co. Ltd 2016). Conceptually similar to steel strands, FRP strands were also developed by twisting a certain number of small-diameter wires. A high load-bearing capacity could be achieved by forming a FRP cable assembled from several strands, for example in the Carbon Fiber Composite (CFCC) system commercialized by Tokyo Rope in Japan (Benmokrane et al. 1997, Tokyo Rope Co. Ltd 2016). FRP Cables with a similar concept, assembled from rods with nominal diameters of $4.0 \mathrm{~mm}$ (Wang et al. 2015) or $12.6 \mathrm{~mm}$ (Zhang et al. 2014), were also developed and studied.

To anchor the tendon on the air and ground sides, mechanical or bonded anchors are commonly used (Schmidt et al. 2012). However, two problems exist in these types of CFRP anchors, which could lead to a premature failure in the anchor and thus not allow to exploit the full tendon capacity: 1) high shear and through-thickness stress concentrations existing at the anchorage are critical due to the anisotropic properties of CFRP fibers; 2) uneven load distributions among the assembled strands or rods occur, i.e. some of them were obviously less loaded compared to others (Wang et al. 2015).

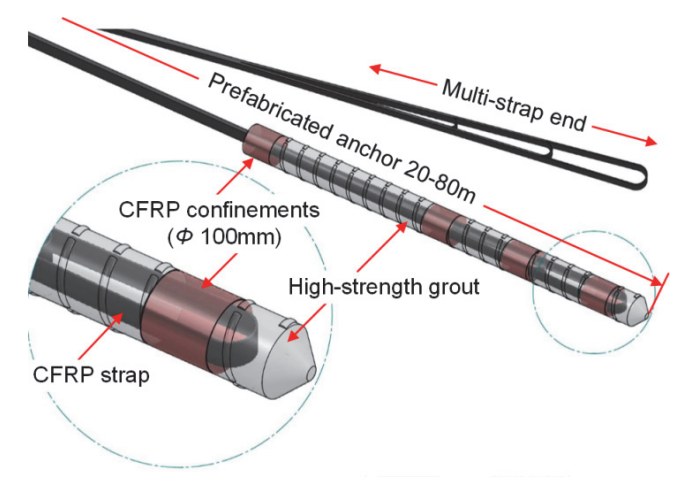

Figure 1 Prestressed and permanent CFRP ground anchor with multi-strap end

A simpler and much more material-tailored anchorage method, based on strap ends, was thus developed (Winistoerfer 1999). A new application of this strap anchorage method for permanent prestressed CFRP ground 
anchors was recently proposed (Fan et al. 2016), which consists of a CFRP tendon with a multi-strap end on the ground side, embedded in a prefabricated high-strength grout cylinder confined with CFRP rings, as shown Figure 1. The main purpose of the rings is to deviate the spreading forces at the embedded strap ends into the cylinder's axial direction and not to increase the grout strength. The grout cylinder is thus stepwise axially loaded by the axial components of the spreading forces. The ground anchor with the prefabricated anchor body can be 20-80 m long and coiled, then transported to the construction site, inserted into the borehole, anchored by injecting fresh standard (normal-strength) grout and finally prestressed to $60 \%$ of the design load.

In a first stage, a CFRP ground anchor with a single-strap end on the ground side was developed (Fan et al. 2016). A CFRP confinement ring, according to the anchor concept (see Figure 1), was installed at the strap end to deviate the spreading forces. A load-bearing capacity of around $500 \mathrm{kN}$ was achieved in pull-out experiments, which is well-tailored for soil applications.

This paper reports on a second development stage, where a two-strap end was conceived on the ground side to increase the load-bearing capacity to more than $1000 \mathrm{kN}$, which normally need a rock media to be anchored. Anchor specimens were pulled out from mortar cylinders confined by steel tubes of different thicknesses which simulated different confinement levels of the rock mass.

\section{EXPERIMENTAL PROGRAM}

\section{CFRP ground anchor specimens}

The CFRP tendons used in this study were produced by Carbo-Link, Fehraltorf, Switzerland, as shown in Figure 2. The tendons were composed of unidirectional UTS50 F24 24k 1600tex D carbon fibers impregnated with XB 3515 AD1571 ACC1573 epoxy resin; the fiber volume fraction was $60 \pm 2 \%$.

The two-strap end of the CFRP tendon was embedded in a 1060-mm-long high-strength grout body with inclined and corrugated surface on the ground side, as shown in Figure 3. A non-shrink sand/cement highstrength grout (SikaGrout-212 provided by Sika Schweiz AG, Switzerland) with a maximum aggregate size of 4 $\mathrm{mm}$ was used. Three 150-mm-long and 2-mm-thick identical CFRP confinement rings, consisting of the same materials as the tendon, were installed around the two strap ends and the division point. The anchor body geometry was designed to fit in boreholes with a minimum diameter of $130 \mathrm{~mm}$.

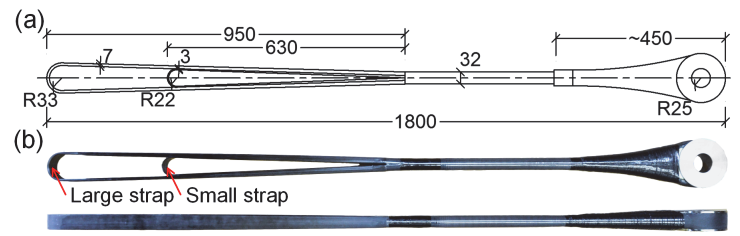

Figure 2 CFRP two-strap tendon

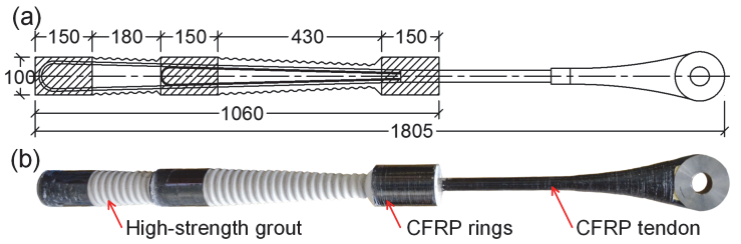

Figure 3 CFRP two-strap anchor

((a) schematic (dimensions in [mm]); (b) photo)

The prefabricated anchor body was inserted into a 1200-mm-long steel tube, simulating a rock mass as shown in Figure 4. The tube was then filled with a fresh sand/cement grout (Sika normal rock anchor mortar, provided by Sika Schweiz AG, Switzerland) with a maximum aggregate size of $0.8 \mathrm{~mm}$. Pull-out experiments were conducted on three anchor specimens with two different tube thicknesses to study the influence of the rock stiffness on the load-bearing capacity of the anchor; an overview of the experimental series is shown in Table 1.

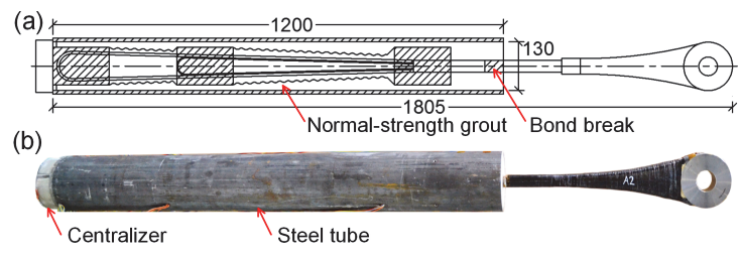

Figure 4 CFRP two-strap anchor specimen: (a) schematic (dimensions in [mm]); (b) photo

Table 1 Summary of experimental results

\begin{tabular}{ccccc}
\hline Specimen & $\begin{array}{c}\text { Tube thickness } \\
(\mathrm{mm})\end{array}$ & $\begin{array}{c}\text { First peak } \\
(\mathrm{kN})\end{array}$ & $\begin{array}{c}\text { Second peak } \\
(\mathrm{kN})\end{array}$ & $\begin{array}{c}K_{\exp }(\mathrm{kN} / \mathrm{mm}) \\
(500 \sim 1200 \mathrm{kN})\end{array}$ \\
\hline ST10-1 & 10 & 1344 & 925 & 92.0 \\
ST10-2 & 10 & 1419 & 133 & 92.0 \\
ST5 & 5 & 1389 & 1402 & 86.2 \\
\hline
\end{tabular}




\section{Experimental setup and instrumentation}

The pull-out experiments were conducted on a Trebel 10MN machine, as shown in Figure 5. The anchor was suspended at the air side through a steel pin to the top fixed beam of the machine. The pulling load was applied to the top surface of the anchor body through a loading frame consisting of a bearing plate, two cross beams, two transverse reinforcements and 18 thread bars; the bars were fixed to the cross beams on one side and to the bottom movable beam of the machine on the other side. The loading was applied to the bottom movable beam in displacement-control mode at a rate of $1 \mathrm{~mm} / \mathrm{min}$. After four load cycles up to $100,300,500$ and $700 \mathrm{kN}$ respectively, the anchor was loaded up to failure.

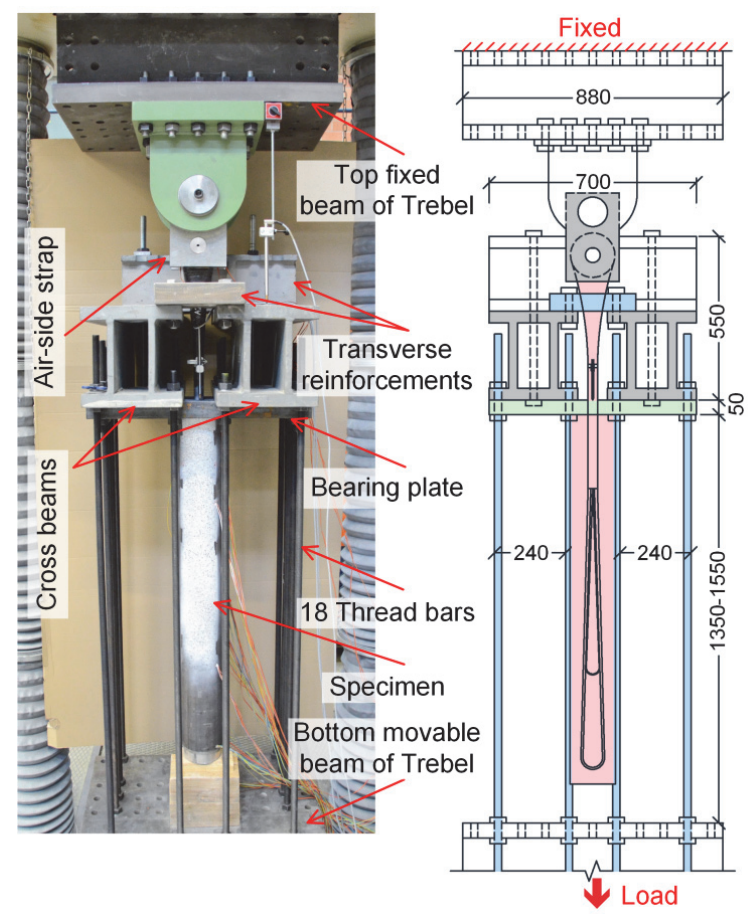

Figure 5 Experimental set-up (dimensions in [mm], DIC white-black paint on tube)

The instrumentation layout is shown in Figure 6. Three types of instruments were used: Linear Variable Differential Transformer (LVDT) transducers, strain gages and Digital Image Correlation (DIC). Two LVDTs were symmetrically fixed on the rod at a distance of $115 \mathrm{~mm}$ from the top surface of the 50 -mm-thick bearing plate to obtain an average pull-out displacement.

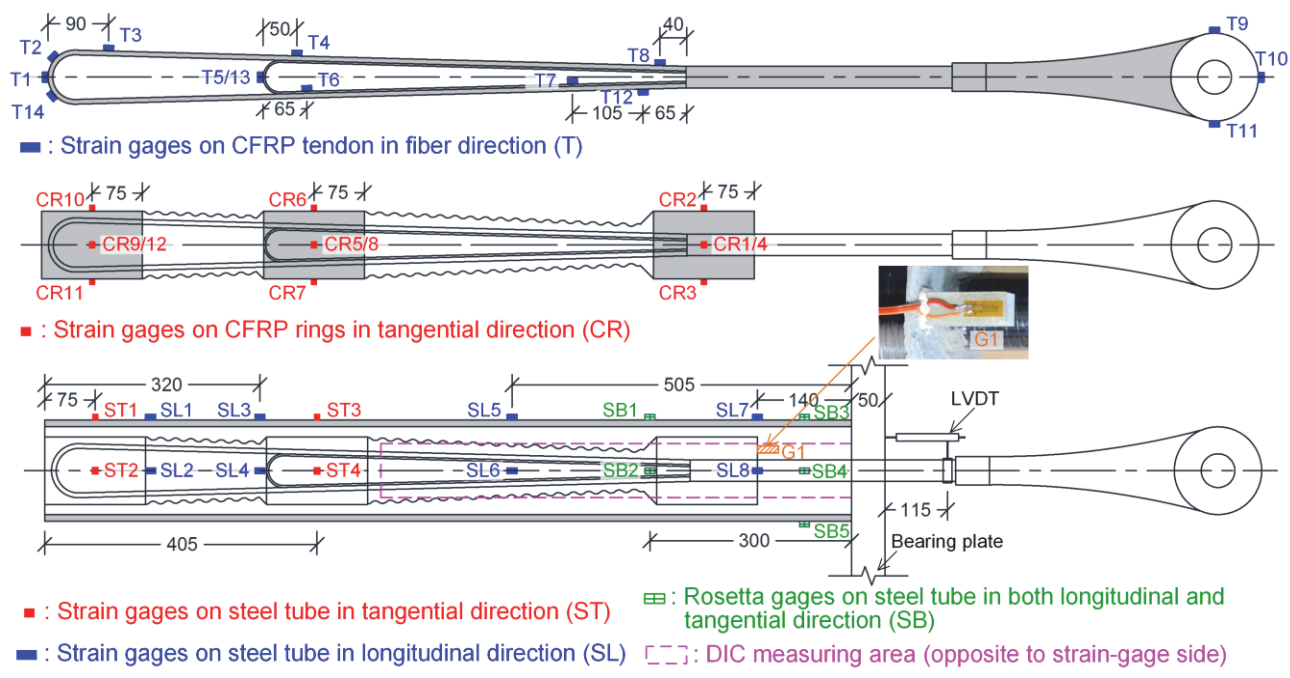

Figure 6 Instrumentation layout 


\section{RESULTS AND DISCUSSIONS}

\section{Load vs pull-out displacement responses and failure modes}

All specimens exhibited similar load vs pull-out displacement responses in the failure cycle up to a first peak, as shown in Figure 7. An almost linear response was observed, except a slight nonlinear behavior at the beginning; the latter was attributed to a progressive debonding at the CFRP/grout interface, which also caused a small residual displacement after the four initial load cycles up to $700 \mathrm{kN}$, as shown in Figure 7 for anchor ST5. The stiffness in the linear range, $K_{\text {exp }}$, assumed as being the slope of the linear segment between 500 and $1200 \mathrm{kN}$, was similar, as shown in Table 1; anchor ST5 exhibited only 6.3\% lower stiffness than the ST10-1/2, which could be attributed to a slightly larger deformation due to the weaker confinement.

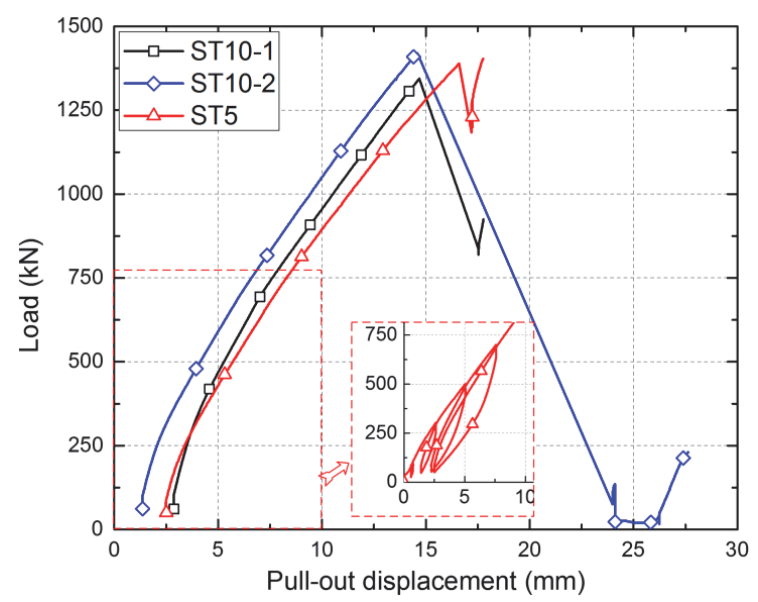

Figure 7 Load vs pull-out displacement responses

The three anchors reached similar loads at the first peak, indicating that the confinement level had low influence on the load-bearing capacity of the anchor. At this first peak, delamination was observed in the visible air-side straps in anchors ST10-1/2, while no damage was recognizable in ST5. After the first peak, the load dropped and increased again to a second peak in all specimens where partial or complete rupture of the air-side strap occurred in anchors ST10-2 and ST5 respectively, see Figure 8. The obtained peak loads are listed in Table 1.

(a) ST10-1:
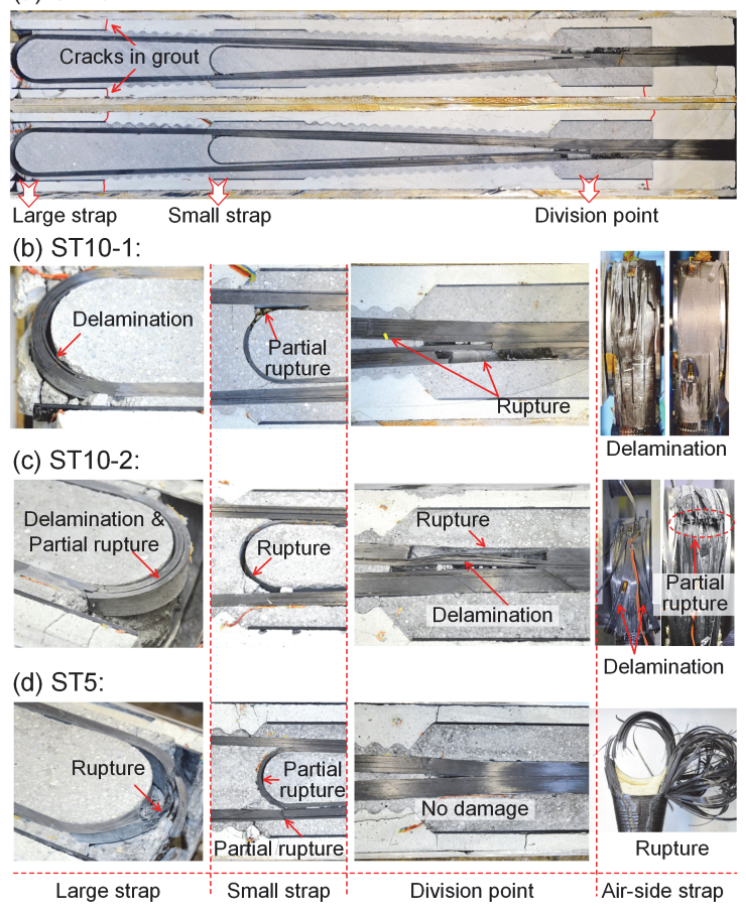

Figure 8 Failure modes: (a) cut view of anchor ST10-1; details in (b) ST10-1, (c) ST10-2, (d) ST5 
After failure, the specimens were cut into two halves in the strap plane, see Figure 8. All anchors exhibited rupture in the embedded CFRP tendons; no compression failure in the grout parts was observed, except small cracks located in the normal-strength grout at the end of the CFRP rings, see Figure 8 (a). In anchor ST10-1, the large and small straps were completely separated from the rod at the division point on one side, while partial rupture or delamination occurred in the semicircles of the small or large straps, see Figure 8 (b). In anchor ST10-2, complete rupture was visible at the division point of the large strap and in the semicircle of the small strap. Furthermore, partial rupture or delamination occurred in the semicircle of the large strap and the division point of the small strap, see Figure 8 (c). In anchor ST5, complete rupture occurred in the semicircle of the large strap and partial rupture in one straight part of the large and at the end of the small strap; no damage was visible at the division point.

\section{Load vs tensile strains in CFRP tendons}

The load vs tensile strain responses in fiber direction of the embedded (ground-side) large and small straps are shown in Figs. 9 and 10 respectively. In all the anchors, the straps were activated progressively from the division point to the small and then to the large strap end due to the progressive loss of bond and subsequent friction at the CFRP/grout interface. The gages close to the division point (T7/8) thus started responding firstly, at lower loads (below $150 \mathrm{kN}$ ), while the gages around the large strap (T1/2/14) were activated lastly, at much higher load (above $350 \mathrm{kN}$ ).
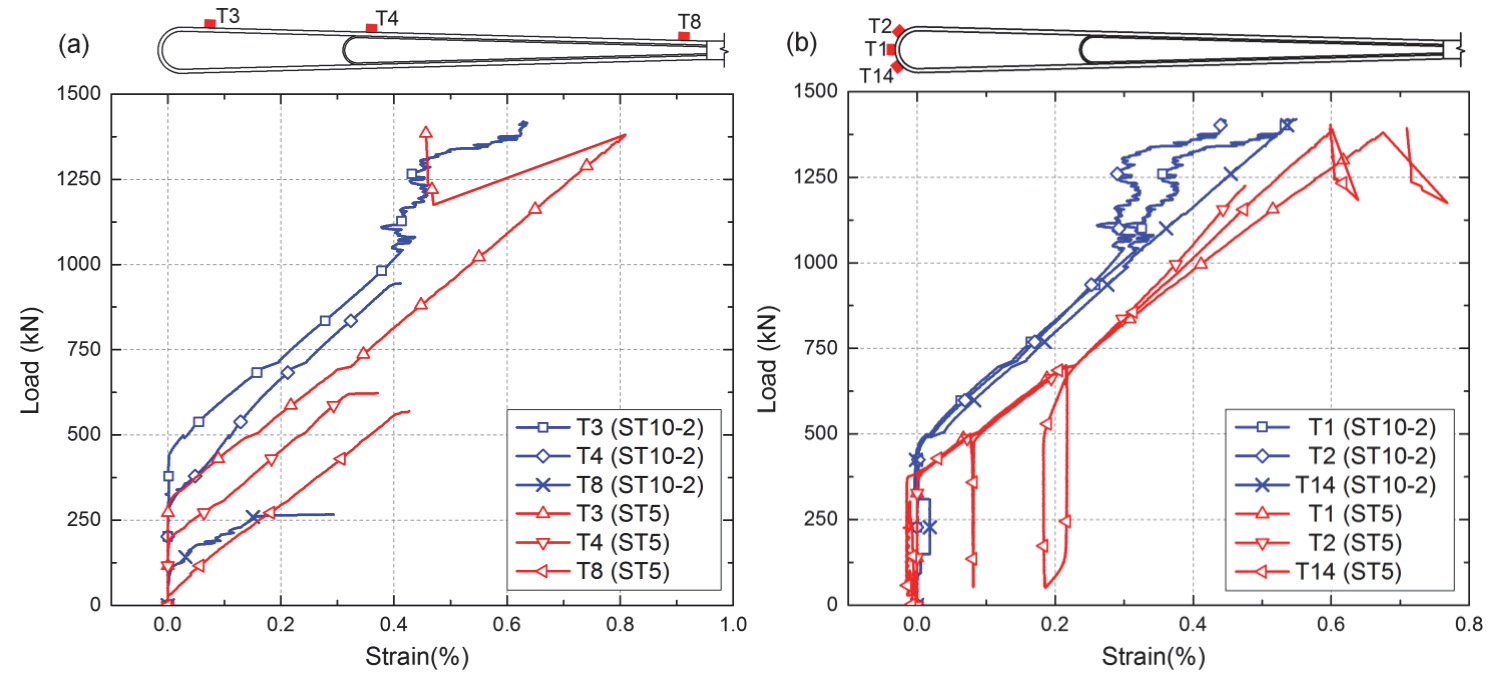

Figure 9 Load vs tensile strain responses of ground-side large strap: (a) along straight segment; (b) at strap end
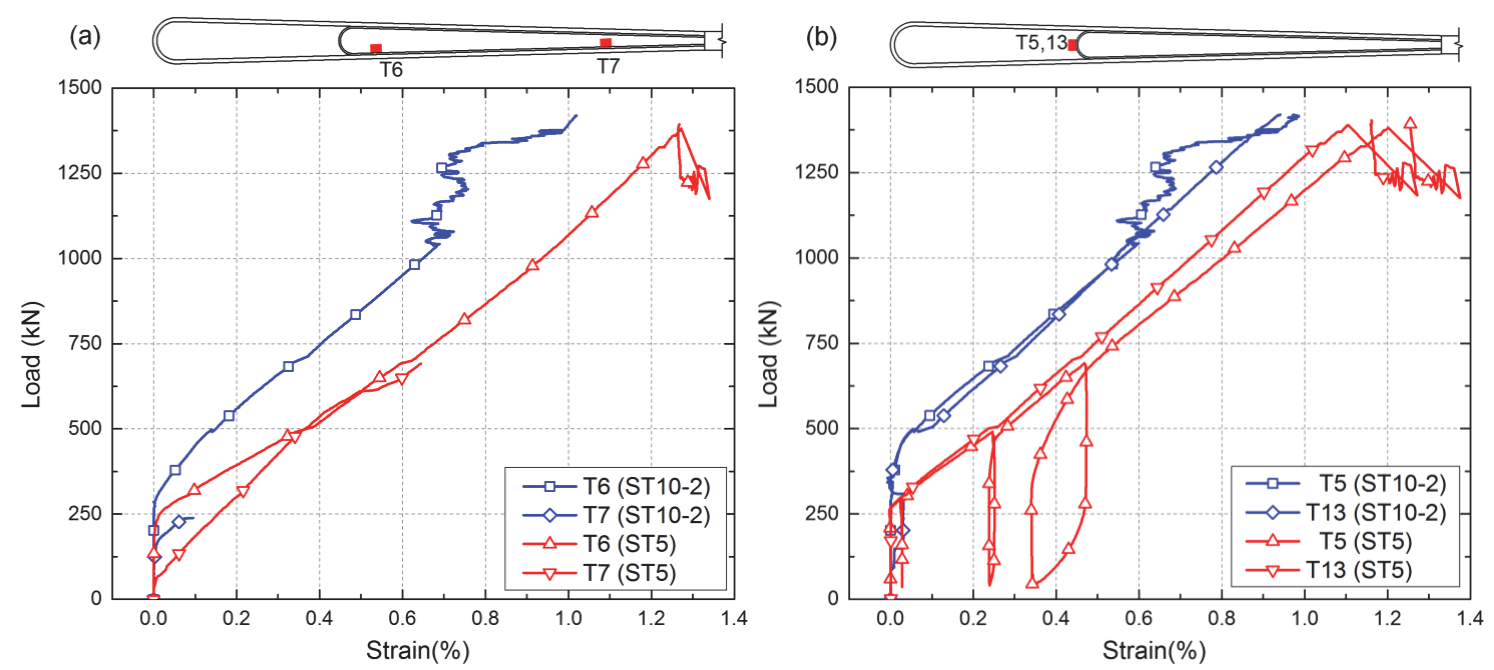

Figure 10 Load vs strain responses of ground-side small strap: (a) along straight segment; (b) at strap end 
The strap activation sequence also depended on the confinement level, i.e. at the higher confinement the strap was activated later due to the higher friction at the CFRP/grout interface. Accordingly, the semicircular parts of the large straps (positions T1/2/14) and small straps (T5/13) in anchor ST10-2 were activated later (at around 450 and $350 \mathrm{kN}$ respectively) compared to ST5 (at around 380 and $270 \mathrm{kN}$ respectively). After the activation, the strain rates in ST10-2 were also slightly lower than in ST5 due to the higher friction.

Due to the early activation, positions T7/8 generally exhibited the maximum strains. However, gages T4/7/8 stopped measuring after certain loads due to the propagating slippage at the CFRP/grout interface. The maximum strains were measured in the small strap of anchor ST5 due to the earlier activation compared to the large strap and lower confinement level; they approached the ultimate strain of the CFRP material. The strains in the large straps, however, remained far below the ultimate strain.

Furthermore, complete recovery of the strap deformation during unloading was prevented by the friction behavior as well, which also led to the residual displacements after unloading during the first four cycles, shown in Fig. 8. The amount of strain recovery also depended on the strap location, i.e. more strain recovery was observed closer to the division point due to the smaller friction, see Fig. 11 (b) and 12 (b).

\section{CONCLUSIONS}

Pull-out experiments were performed on three CFRP ground anchors with two-strap ends embedded in a prefabricated high-strength grout anchor body on the ground side. The anchor body was embedded in normal strength grout confined with steel tubes of different thicknesses to simulate the confinement of different rock masses.

The results showed that the targeted $1000-\mathrm{kN}$ anchor capacity was reached. Failure occurred in the CFRP tendons at different positions on the embedded air- and ground- sides which proved an almost uniform use of the capacities of the different strap components. Furthermore, the conceptual elements to prevent grout failure, i.e. selection of high-strength grout in the anchor body, CFRP confinement rings to balance and deviate spreading forces and the complex conical anchor body shape to introduce the forces into the normal grout proved to be effective and well-tailored, grout failure did not occur.

\section{ACKNOWLEDGMENTS}

The authors wish to acknowledge the support and funding of this research by the Swiss Federal Commission for Technology and Innovation CTI (Grant No. KTI 14139.2 PFIW-IWF) and industry partners F.J. Aschwanden AG in Lyss, Carbo-Link AG in Fehraltorf (supplier of the CFRP tendon specimens), and Sika Schweiz AG in Zurich, Switzerland (supplier of the cement grout).

\section{REFERENCES}

Benmokrane, B., Xu, H., and Nishizaki, I. (1997). "Aramid and carbon fibre-reinforced plastic prestressed ground anchors and their field applications." Canadian Journal of Civil Engineering, 24(6), 968-985.

Fan, H., Vassilopoulos, A. P., and Keller, T. (2016). "Pull-out behavior of CFRP single-strap ground anchors." Proceedings, 17th European Conference on Composite Materials. Munich, Germany, June.

Schmidt, J. W., Bennitz, A., Täljsten, B., Goltermann, P., and Pedersen, H. (2012). "Mechanical anchorage of FRP tendons-A literature review." Construction and Building Materials, 32, 110-121.

Tokyo Rope Co. Ltd. (2016). "Summary of application projects." <https://isabou.net/sponsor/nmanchor/sekou.asp> (May 02, 2016).

Wang, X., Xu, P., Wu, Z., and Shi, J. (2015). "A novel anchor method for multitendon FRP cable: manufacturing and experimental study." Journal of Composites for Construction, ASCE, 19(6), 04015010.

Winistoerfer, A. U. (1999). Development of non-laminated advanced composite straps for civil engineering applications, PhD Thesis, University of Warwick, Coventry, U.K.

Zhang, K., Fang, Z., Nanni, A., Hu, J., and Chen, G. (2014). "Experimental Study of a Large-Scale Ground Anchor System with FRP Tendon and RPC Grout Medium." Journal of Composites for Construction, 19(4), 04014073. 